\title{
Finite Rate Chemistry Effects in Turbulent Reacting Flows
}

\author{
R.P. LINDSTEDT ${ }^{1}$, S.A. LOULOUDI ${ }^{1}$, J.J. DRISCOLL ${ }^{2}$ and V. SICK ${ }^{2}$ \\ ${ }^{1}$ Department of Mechanical Engineering, Imperial College London, London, UK; \\ E-mail: p.lindstedt@imperial.ac.uk \\ ${ }^{2}$ Department of Mechanical Engineering, The University of Michigan, USA
}

Received 30 June 2003; accepted in revised form 17 December 2003

\begin{abstract}
The classical "fast chemistry" analysis by Damköhler remains a common basis for calculation methods aimed at turbulent reacting flows. Perturbation approaches can be used to introduce finite rate chemistry effects, particularly where a distinct chemical time-scale separation is present, though more comprehensive techniques, e.g. based on a transported joint probability density function (JPDF), are typically required. Potential difficulties with the JPDF technique include issues related to the intrinsic structure of turbulent flames, particularly at low Reynolds numbers, and models for molecular mixing. The ability to predict the formation of NO is particularly interesting in this context given the strong sensitivity to chemical kinetic and non-adiabatic effects. The current work initially provides an assessment of uncertainties in the formation chemistry of NO in the context of new quantitative measurements, obtained in non-premixed laminar methane/air counterflow flames using ps-LIF, and subsequently explores how these translate to turbulent flames. A consistent systematically reduced (16 independent, 4 dependent and 28 steady state scalars) reaction mechanism is applied to model the turbulent flames of Barlow and co-workers $(8200 \leq R e \leq 44000)$. The highest $R e$ number flame additionally permits an investigation into the ability of the transported JPDF technique to deal with emissions of nitric oxide in flames close to global extinction. The work shows that the technique has the potential to reproduce NO levels and conditional PDFs under conditions with significant local extinction/re-ignition to within the uncertainties associated with the principal elementary reaction steps.
\end{abstract}

Key words: turbulent reacting flows, emissions of nitric oxide, transported PDF methods

\section{Introduction}

The formation of nitric oxide is kinetically rather than thermodynamically controlled and calculation procedures must be able to represent interactions between turbulence and finite-rate chemistry over a wide range of Damköhler numbers. The practical relevance of the problem stems partly from an increased interest in stratified combustion processes (e.g., gasoline direct-injection), the need to stabilize lean partially premixed gas turbine combustors, e.g. through diffusion flame pilots, and a desire to reduce signatures from high performance propulsion devices. The latter increasingly operate close to stability limits and calculation procedures must be able to account for the effects of local extinction and re-ignition events upon computed emissions levels. 
Past work aimed at establishing the effects of thermochemical uncertainties on computed NO levels has focused on measurements of chemical species in a wide range of premixed laminar flames [4, 20, 25]. Such work has proved instrumental in evaluating the effects associated with uncertainties in rate constants and reaction paths. Other studies have included measurements of species profiles in both premixed [4, 20,25] and non-premixed flames [35] artificially seeded with NO to explore the NO destruction chemistry. It is evident that the prompt $\mathrm{NO}$ production pathway $\mathrm{CH}+\mathrm{N}_{2} \rightarrow \mathrm{HCN}+\mathrm{N}$ exerts a dominant influence in laminar flames [27]. The uncertainties associated with the initiating step are reflected in investigations of turbulent diffusion flames pursued as part of successive International Workshops on the Measurement and Computation of Turbulent Non-premixed Flames (TNF) $[1,2]$. The associated flames have been used extensively as test-cases for the assessment of models for NO formation. The computational studies of Coelho and Peters [7] and Pitsch and Steiner [30] feature RANS and LES approaches for the flow field, respectively, combined with unsteady flamelet modeling for the scalar field. A conditional moment closure (CMC) has been implemented by Roomina and Bilger [32], whereas Lindstedt et al. [23] and Tang et al. [38] applied transported joint probability density function (JPDF) methods. Encouraging predictions have been obtained at moderate Reynolds numbers $(R e \sim 22400)$ though uncertainties in the thermochemistry and radiative heat losses have obscured findings. Consistent over-predictions of peak NO levels have also been a common difficulty.

Much of the validation of detailed and systematically reduced reaction mechanisms has been based on the use of NO concentration profiles determined through LIF techniques. The range of rate coefficients that is available (and used in various mechanisms) for the initiating reaction necessitates further investigation. A primary objective of the current paper is thus to assess current uncertainties in the formation chemistry of $\mathrm{NO}$ in the context of new quantitative measurements of NO concentration profiles in non-premixed methane/air counterflow flames $[12,35]$ and to explore how these translate to turbulent flames covering a wide range of Reynolds numbers. A further objective is to investigate the ability of the transported JPDF and steady state flamelet techniques to predict emissions of nitric oxide in the presence of significant local extinction and subsequent relight.

\section{Principal Thermochemical Uncertainties}

A number of studies aimed at the development of detailed kinetics for the modeling of nitric oxides have considered both premixed (e.g., [26]) and non-premixed combustion (e.g., [22]). In contrast to premixed flames (cf. [20]), the systematic assessment of the uncertainties associated with the modeling of $\mathrm{NO}_{x}$ in diffusion flames has received comparatively little attention. Sick et al. [35] investigated the recommendations by Deon et al. [11], Lindackers et al. [21] and GRI-Mech. 2.11 by Frenklach et al. [15] for the prompt NO formation channel in a range of 
counterflow $\mathrm{CH}_{4} /$ Air diffusion flames. The principal uncertainties associated with the $\mathrm{CH}$ chemistry were outlined and three key reaction steps are given below.

$$
\begin{aligned}
\mathrm{N}_{2}+\mathrm{CH} & =\mathrm{HCN}+\mathrm{N} \\
\mathrm{O}_{2}+\mathrm{CH} & =\mathrm{CHO}+\mathrm{O} \\
\mathrm{H}_{2} \mathrm{O}+\mathrm{CH} & =\mathrm{CH}_{2} \mathrm{OH}
\end{aligned}
$$

Sick et al. [35] tentatively concluded that the prompt channel (I) rate determination by Dean et al. [11] is broadly consistent with flame data. It was also shown that the rate suggested by Lindackers et al. [21] yielded an over-prediction of NO by around $50 \%$ in laminar flames. By contrast, the rate suggested by Frenklach et al. [15] was shown to have a tendency to result in under-predictions of NO levels by around a factor of 2 and a subsequent revision of the GRI-Mech 2.11 was aimed at alleviating the problem. The study by Barlow et al. [3] of partially premixed $\mathrm{CH}_{4} /$ Air flames is broadly consistent with the above findings though it was found that GRI-Mech. 3.0 significantly over-predicted NO formation. The prompt channel has also been studied theoretically by Miller and Walch [27] and the latter study showed good agreement with the experimental work of Dean et al. [11]. The two expressions may be viewed as indicative of current uncertainties in rate data. It is, however, evident that a quantitative determination of the $\mathrm{CH}$ radical in laminar diffusion flames would be most helpful in further reducing current uncertainties. Work in premixed laminar flames, e.g. Juchmann et al. [20] and Berg et al. [4], has proved very helpful in the past and more recent efforts, e.g. Evertsen et al. [13], have further emphasised current uncertainties. The prompt NO formation rates of Lindackers et al. [21], Dean et al. [11] and Miller and Walch [27] are shown in Table I and are plotted as a function of temperature in Figure 1. The $\mathrm{CH}$ oxidation steps (II, III) are retained from the study by Sick et al. [35] with $k_{I I}=7.5 * 10^{10} \mathrm{~m}^{3} \mathrm{kmol}^{-1} s^{-1}$ [24] and $k_{I I I}=5.17 * 10^{9} \mathrm{e}^{3160 / R T} \mathrm{~m}^{3} \mathrm{kmol}^{-1} s^{-1}[41]$.

\section{Quantitative Laminar Flame NO Data}

Laser-induced fluorescence (LIF) has become increasingly popular as a nonintrusive, spatially precise probe of NO and other important related species [9]. When applied with conventional (3-20 ns) lasers, linear-LIF produces signal

Table I. Reaction rate constants for prompt NO formation presented in the form $A_{i} T^{\beta_{i}} \exp \left(-E_{i} / R T\right)$. Units are in $\mathrm{K}$, kmole, $\mathrm{m}^{3}$, $\mathrm{s}$ and $\mathrm{J} / \mathrm{mole}$.

\begin{tabular}{llll}
\hline$k_{i}$ & $A_{i}$ & $\beta_{i}$ & $E_{i}$ \\
\hline Lindackers et al. [21] & $6.60 \times 10^{8}$ & 0 & 58200 \\
Dean et al. [11] & $4.40 \times 10^{9}$ & 0 & 91956 \\
Miller and Walch [27] & $3.68 \times 10^{4}$ & 1.42 & 86702 \\
\hline
\end{tabular}




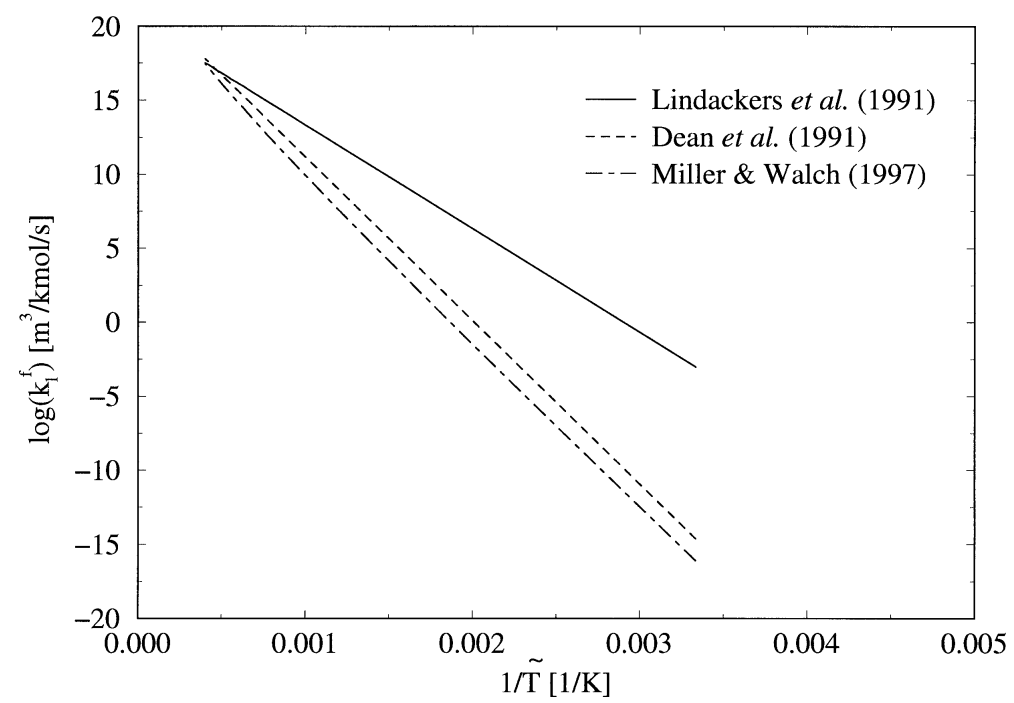

Figure 1. Reaction rate constants for prompt NO formation as a function of temperature following Lindackers et al. [21] (solid line), Dean et al. [11] (dashed line) and Miller and Walch [27] (dot-dashed line).

intensities that are dominated by collisional quenching effects in atmospheric pressure flames. Consequently, measurements [28] and modeling [29, 37] of quenching rate coefficients for the $\mathrm{NO} A^{2} \Sigma^{+}$state by various chemical species have been used to evaluate such data. However, the process requires detailed knowledge of temperature and concentrations of the species responsible for quenching, and such information often comes from the model being tested, or, less frequently, from measurements [6]. An alternative approach, excitation with lasers of short pulse duration compared to quenching rates, can be used to directly measure the LIF lifetime. The approach has been used with ns-pulse lasers in low pressure flames [37]. In atmospheric pressure flames, nanosecond pulses are too long to make LIF lifetime measurements, with a few exceptions such as formaldehyde [34]. Instead, lasers capable of producing picosecond pulses are used; time-resolved picosecondlaser based LIF (ps-LIF) experiments have been used to measure concentrations of $\mathrm{OH}$ (e.g., [5]) and $\mathrm{CH}$ [31] in flames, and to map fluorescence lifetimes of NO in flames seeded with NO $[33,39]$. The ability to temporally resolve the NO fluorescence signal allows determination of an effective quenching rate, consisting of contributions from all species.

The application of such approaches to quantitative NO measurements in nonpremixed counterflow flames was shown by Driscoll et al. [12]. The picosecond laser system used [40] was based on a distributed feedback dye laser (DFDL) operating near $677 \mathrm{~nm}$ at a $20 \mathrm{~Hz}$ repetition rate with the ability to perform automated wavelength scans and an active wavelength stabilization system. Frequency-tripling to $226 \mathrm{~nm}$ yielded output pulses with a FWHM bandwidth of $1.1 \pm 0.1 \mathrm{~cm}^{-1}$, a FWHM 
pulse width of $55 \mathrm{ps}$, and maximum UV pulse energies of $150 \mu \mathrm{J}$, with energy fluctuations of $\pm 8 \%$. The rectangular beam cross section in the measurement area was $1.6 \pm 0.2 \mathrm{~mm}$ wide by $200 \pm 15 \mu \mathrm{m}$ high (this dimension determined the spatial resolution of the measurements as this is in the direction of the gradients in the flame). Over the $1.6 \mathrm{~mm}$ wide beam width the flame can be regarded as essentially flat in terms of spatial resolution. Fluorescence signals were spectrally dispersed with $0.125 \mathrm{~m}$ focal length monochromator whose bandpass was centered near 241 $\mathrm{nm}$ and had a width of $20 \mathrm{~nm}$ in order to transmit the NO $A-X\left(v^{\prime}=0 \rightarrow v^{\prime \prime}=1\right)$ and $\left(v^{\prime}=0 \rightarrow v^{\prime \prime}=2\right)$ bands. The detector was a UV-sensitive microchannelplate (MCP) intensified photomultiplier tube (PMT; Hamamatsu R3809-52) with a rise and fall time of 150 and $350 \mathrm{ps}$, respectively. The PMT output was recorded using a 12 bit transient digitizer (Tektronix SCD-5000) with a rise/fall time of $60 \mathrm{ps.}$ NO molecules were excited through the $\mathrm{P}_{1}$ branch bandhead peak near $226.362 \mathrm{~nm}$ because it consists of overlapping $\mathrm{P}_{1}$ transitions ranging from $J=7.5$ to 10.5 and $\mathrm{P}_{2}(J=22.5)$, providing stronger absorption and reduced sensitivity to temperature over the range probed $(300 \mathrm{~K}$ to $2000 \mathrm{~K}$ ). In addition, this excitation wavelength did not produce significant emission from Schumann-Runge bands of $\mathrm{O}_{2}$ in dispersed fluorescence measurements.

As described by Driscoll et al. [12], the wavelength and temperature dependent spectra were simulated to account for temperature influences on the measured signals. Besides calibrating the LIF signals with measurements of $\mathrm{NO}(30 \mathrm{ppm})$ in a mixture with $N_{2}$ flowing through the burner head, a number of other corrections were needed to fully quantify the measurements across the flame. These effects include the spectral efficiency of the detection system, laser beam and signal absorption, signal attenuation due to shadowing effect by the burner head, and quenching (as directly measured via the time-resolved ps measurements). The technique is here applied to laminar diffusion methane/air flames established on a Tsuji-type counterflow burner that was replicated from previous work [35] with the rate of strain covering a range from $59 \mathrm{~s}^{-1}$ to $269 \mathrm{~s}^{-1}$. Spatial profiles were obtained by vertically translating the burner head within the housing using micrometercontrolled translation stages. The burner axis (along the cylinder) was rotated with respect to the laser beam by $20^{\circ}$ as it was found that this substantially reduced the effect of beam steering due to thermal gradients. Temperature also has a large impact upon computed NO levels and here measurements were performed with a broadband CARS setup [12] probing $\mathrm{N}_{2}$.

The fluorescence decays were analyzed to yield both the initial signal at $t=0$, the lifetimes $\tau$, and the quenching rates $Q$. Extrapolation to $t=0$ was used for the concentration measurements rather than normalizing the measured integrated fluorescence signal with the measured lifetime though both approaches give the same result [12]. The uncertainty in the temperature measurements affects the concentration measurements through the density correction and through the line overlap/thermal population correction. This contribution was calculated to be $3.2 \%$ based on the estimated $30 \mathrm{~K}$ uncertainty at peak temperatures. The uncertainty 
associated with beam energy fluctuation corrections is $1 \%$. The neutral density filters used to attenuate signal add an additional $4 \%$ to the overall uncertainty from sampling analysis. Assumptions used in the determination of the excitation fraction (linear excitation without saturation) imposes an additional 10\% uncertainty (estimated). A systematic error of $10 \%$ was imposed to account for possible wavelength shifts of the laser and the resulting effect on excitation. Finally, random error was determined to be $5 \%$. The addition of these values in quadrature yields an overall uncertainty of $16 \%$ in the NO concentration measurements. The uncertainty in measurements close to the burner in the high strain rate flame is estimated to be as large as $30 \%$ due to a large uncertainty in the measured temperature.

The differences in strain rates for the three flames investigated are large enough to produce substantially different temperature profiles as shown in Figure 2. The flame with the lowest strain rate is stabilized with the flame front farthest away from the burner head but still the width of the overall flame is large enough to cause the temperature close to the surface to be substantially higher than for the other flames indicating some heat loss to the surface. The fitted temperature profiles used in the computations are also shown and the measured temperatures were also used for the corrections to the LIF signals [35]. Adiabatic computations indicate heat losses $\sim 4-5 \%$ for the current flames and the measured temperature profiles are considered more accurate. Accordingly, results obtained with fitted temperature profiles for the three different flames are shown in Figure 3. While the peak concentrations for the lower strain rate flames $\left(\alpha=59 \mathrm{~s}^{-1}\right.$ and $\left.119 \mathrm{~s}^{-1}\right)$ are approximately the same at $\sim 80$ $\mathrm{ppm}$ the peak concentration for the high strain rate flame drops to $\sim 50 \mathrm{ppm}$. The NO concentrations determined by Sick et al. [35] suggested a peak value of $\sim 125 \mathrm{ppm}$

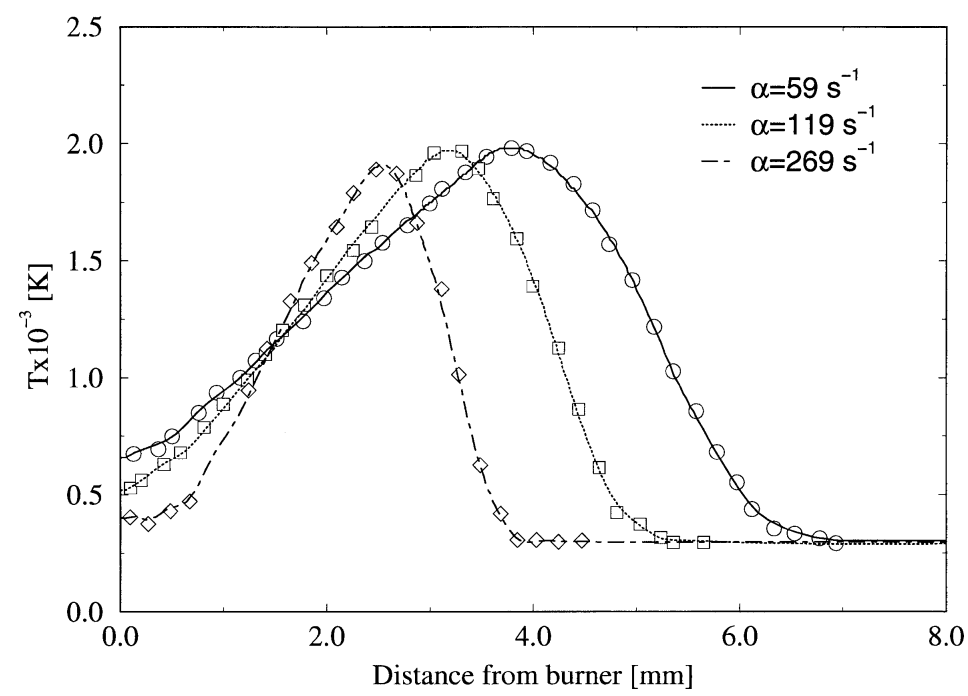

Figure 2. Temperature profiles for the three laminar flames studied. The profiles were measured with broadband CARS of $\mathrm{N}_{2}$. 


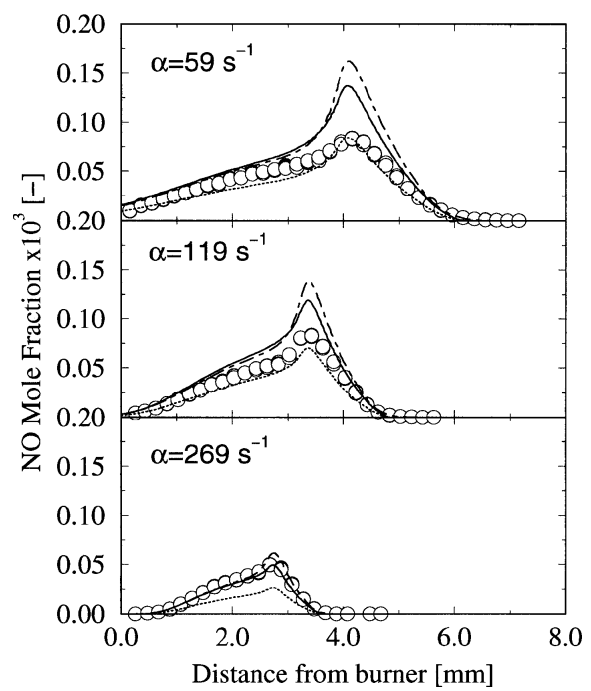

Figure 3. NO concentration profiles in methane/air counterflow laminar diffusion flames at different strain rates. The symbols represent experimental data and the lines predictions obtained with the rate of Dean et al. [11] (solid line), Miller and Walch [27] (dotted line) and GRI-Mech. 3.0 by Frenklach et al. [15] (dot-dashed line).

at a rate of strain of $121 \mathrm{~s}^{-1}$. The current computations essentially bracket the new experimental data. By comparison, GRI-Mech. 2.11, not shown as mechanism has been superceeded, tends to fall below the values computed with the Miller and Walch [27] expression with those of GRI-Mech. 3.0 above the Dean et al. [11] line. The apparent under-prediction obtained with the Miller and Walch expression for the $\alpha=$ $269 \mathrm{~s}^{-1}$ flame needs to be treated with some caution as computations with a constant heat loss factor of $4 \%$ indicate that the spatial resolution of the CARS technique may contribute somewhat to an under-estimate of the peak temperature for this flame.

\section{Calculation Procedure for Turbulent Flames}

The calculation procedure follows that of Lindstedt et al. [23] and has been shown to result in good predictions of flow fields and major scalars. The velocity field is thus modelled using the second moment closure of Speziale et al. [36] and the generalized gradient diffusion formulation of Daly and Harlow [10] is used for the closure of triple moment and pressure transport terms. The calculations feature the standard closure for the turbulent kinetic energy dissipation rate [19], with the $C_{\varepsilon 2}$ constant adjusted from 1.92 to 1.8 in order to improve the predicted rate of spread. The equation for the evolution of the JPDF is solved using the Monte Carlo approach, featuring moving particles in a Lagrangian framework, of Hůlek and Lindstedt [17] and molecular mixing is modeled using the modified Curl's model of Janicka et al. [18]. Hůlek and Lindstedt [17] considered joint velocity-scalar statistics. By contrast, the current work features joint scalar statistics and hence a model is required for the transport of the JPDF in physical space. The latter is 
here obtained through a gradient diffusion approximation with the corresponding "turbulent Prandtl number" $(P r)$ set to a value of unity and the velocity-scalar time-scale ratio is assumed constant with $C_{\phi}=2.3$.

The chemistry adopted in the present work is that used by Lindstedt et al. [23], with the prompt rate (I) updated as indicated, and the systematically reduced form features 20 solved species $\mathrm{H}, \mathrm{O}, \mathrm{OH}, \mathrm{HO}_{2}, \mathrm{H}_{2} \mathrm{O}, \mathrm{H}_{2}, \mathrm{O}_{2}, \mathrm{CH}_{4}, \mathrm{CH}_{3}, \mathrm{CO}, \mathrm{CO}_{2}$, $\mathrm{C}_{2} \mathrm{H}_{2}, \mathrm{C}_{2} \mathrm{H}_{4}, \mathrm{C}_{2} \mathrm{H}_{6}, \mathrm{~N}_{2}, \mathrm{~N}_{2} \mathrm{O}, \mathrm{NO}, \mathrm{NO}_{2}, \mathrm{HCN}$ and $\mathrm{NH}_{3}$ of which 16 are independent scalars. Steady-state approximations are applied to 28 species $\mathrm{C}, \mathrm{CH},{ }^{1} \mathrm{CH}_{2},{ }^{3} \mathrm{CH}_{2}$, $\mathrm{CHO}, \mathrm{CH}_{2} \mathrm{O}, \mathrm{CH}_{2} \mathrm{OH}, \mathrm{CH}_{3} \mathrm{O}, \mathrm{C}_{2}, \mathrm{C}_{2} \mathrm{H}, \mathrm{C}_{2} \mathrm{H}_{3}, \mathrm{C}_{2} \mathrm{H}_{5}, \mathrm{C}_{2} \mathrm{HO}, \mathrm{C}_{2} \mathrm{H}_{2} \mathrm{O}, \mathrm{N}, \mathrm{NH}, \mathrm{NH}_{2}$, $\mathrm{N}_{2} \mathrm{H}_{2}, \mathrm{~N}_{2} \mathrm{H}, \mathrm{HNO}, \mathrm{HNO}_{2}, \mathrm{CN}, \mathrm{NCO}, \mathrm{HOCN}, \mathrm{HNCO}, \mathrm{HCNO}, \mathrm{H}_{2} \mathrm{CN}$ and $\mathrm{H}_{2} \mathrm{O}_{2}$. The chemical source term is computed via a direct integration technique featuring a Newton method with the Jacobian evaluated analytically.

The solution procedure features an implicit parabolic formulation in a transformed streamfunction based coordinate system. The cross-stream direction is discretized by means of 70 computational cells. An average of 100 particles/cell is used and about 1900 axial steps are used to cover the flame length of $\sim 80$ jet diameters. The velocity and scalar fields are initialised by fitting the experimental data at the burner outlet.

In the current work radiative heat transfer effects are accounted for through the inclusion of the RADCAL method [16] and enthalpy as a solved scalar. The effects of introducing the radiation model are readily apparent from comparisons of the measured and computed radiant fractions $\left(f_{\text {rad }}\right)$ defined as the ratio of the total radiated power $\left(\dot{S}_{\text {rad }}\right)$ to the power released during combustion.

$$
f_{\text {rad }}=\frac{\dot{S}_{\text {rad }}}{\dot{m}_{\text {fuel }} \Delta H_{\text {comb }}} .
$$

In the above expression $\dot{m}_{\text {fuel }}$ is the mass flow rate of the fuel in the fuel stream at the exit of the nozzle given by

$$
\dot{m}_{\text {fuel }}=\rho_{F} \tilde{u}_{F, B} \pi(D / 2)^{2} X_{\mathrm{CH}_{4}} \frac{M_{\mathrm{CH}_{4}}}{M_{\text {mix }}}
$$

where $\rho_{F}$ is the density of the fuel stream $\left(1.15 \mathrm{~kg} / \mathrm{m}^{3}\right), \tilde{u}_{F, B}$ is the fuel bulk jet velocity, as shown in Table II, $X_{\mathrm{CH}_{4}}$ is the fuel mole fraction (0.25), and $M_{\mathrm{CH}_{4}}$ and $M_{\text {mix }}$ denote the molecular weight of $\mathrm{CH}_{4}(16 \mathrm{~kg} / \mathrm{kmole})$ and the fuel mixture $(25.65 \mathrm{~kg} / \mathrm{kmole})$, respectively. Further, $\Delta H_{\text {comb }}$ is the heat of combustion of

Table II. Operating conditions for the methane flames computed.

\begin{tabular}{lllccll}
\hline Flame & $R e$ & $\tilde{u}_{\mathrm{F}, \mathrm{B}}(\mathrm{m} / \mathrm{s})$ & $\tilde{u}_{\mathrm{F}, \mathrm{C}}(\mathrm{m} / \mathrm{s})$ & $\tilde{u}_{P}(\mathrm{~m} / \mathrm{s})$ & $T_{\mathrm{F}}, T_{\mathrm{A}}(\mathrm{K})$ & $T_{P}(\mathrm{~K})$ \\
\hline Flame B & 8200 & 18.2 & 22.3 & 6.8 & 298 & 1932 \\
Flame D & 22400 & 49.6 & 63.1 & 11.4 & 298 & 1932 \\
Flame F & 44800 & 99.2 & 126.2 & 22.8 & 298 & 1932 \\
\hline
\end{tabular}


methane $\left(-55.5 \cdot 10^{6} \mathrm{~J} / \mathrm{kg}\right.$-methane), while $\dot{S}_{\text {rad }}$ is obtained from

$$
\dot{S}_{\mathrm{rad}}=\sum_{x=0}^{x_{\max }} \sum_{A=0}^{A_{\max }} Q_{\mathrm{RAD}} \mathrm{d} A \mathrm{~d} x
$$

where $x_{\max } / D=80, A_{\max }=\pi r_{\max }^{2}$ with $r_{\max }$ the thickness of the boundary layer at each computational step. Further, $Q_{\mathrm{RAD}}$ is given by

$$
Q_{\mathrm{RAD}}=4 \sigma_{\mathrm{SB}} \sum_{i=1}^{K} p_{i} a_{p, i}\left(T^{4}-T_{b}^{4}\right)
$$

where $\sigma_{\mathrm{SB}}$ is the Stefan-Boltzmann constant $\left(\sigma_{\mathrm{SB}}=5.669 \times 10^{-8} \mathrm{~W} / \mathrm{m}^{2} \cdot K^{4}\right), p_{i}$ the partial pressure of species " $i$ " in atmospheres, $a_{p, i}$ the Planck mean absorption coefficient of species " $i$ " in $\mathrm{m}^{-1} \cdot \mathrm{atm}^{-1}, T$ the local flame temperature and $T_{b}$ is the background temperature equal to $298.15 \mathrm{~K}$. The partial pressure $p_{i}$ is defined from the species molar fraction $X_{i}$ and the local pressure $p$

$$
p_{i}=X_{i} p
$$

and $a_{p, i}$ for $\mathrm{H}_{2} \mathrm{O}$ and $\mathrm{CO}_{2}$ are given by

$$
\begin{aligned}
a_{p, i}= & c_{0, i}+c_{1, i}\left(\frac{1000}{T}\right)+c_{2, i}\left(\frac{1000}{T}\right)^{2}+c_{3, i}\left(\frac{1000}{T}\right)^{3} \\
& +c_{4, i}\left(\frac{1000}{T}\right)^{4}+c_{5, i}\left(\frac{1000}{T}\right)^{5} .
\end{aligned}
$$

The coefficients $c_{m, i}$ for $m=0,1, \ldots, 5$ are shown in Table III. A fourth-order polynomial in temperature is used for $\mathrm{CH}_{4}$

$$
\begin{aligned}
a_{p, i}= & \left(0.66334 \times 10^{1}\right)-\left(0.35686 \times 10^{-2}\right) T+\left(0.16682 \times 10^{-7}\right) T^{2} \\
& +\left(0.25611 \times 10^{-9}\right) T^{3}-\left(0.26558 \times 10^{-13}\right) T^{4}
\end{aligned}
$$

and a fit for $\mathrm{CO}$ is given in two temperature ranges with the corresponding coefficients demonstrated in Table IV.

$$
a_{p, i}=c_{0, i}+T\left(c_{1, i}+T\left(c_{2, i}+T\left(c_{3, i}+T c_{4, i}\right)\right)\right) .
$$

Table III. Planck mean absorption coefficients for $\mathrm{H}_{2} \mathrm{O}$ and $\mathrm{CO}_{2}$.

\begin{tabular}{lll}
\hline$a_{p, i}$ & $\mathrm{H}_{2} \mathrm{O}$ & $\mathrm{CO}_{2}$ \\
\hline$c_{0}, i$ & $-0.23093 \times 10^{0}$ & $+0.18741 \times 10^{2}$ \\
$c_{1}, i$ & $-0.11239 \times 10^{1}$ & $-0.12131 \times 10^{3}$ \\
$c_{2}, i$ & $+0.94153 \times 10^{1}$ & $+0.27350 \times 10^{3}$ \\
$c_{3}, i$ & $-0.29988 \times 10^{1}$ & $-0.19405 \times 10^{3}$ \\
$c_{4}, i$ & $+0.51382 \times 10^{0}$ & $+0.56310 \times 10^{2}$ \\
$c_{5}, i$ & $-0.18684 \times 10^{-4}$ & $-0.58169 \times 10^{1}$ \\
\hline
\end{tabular}


Table IV. Planck mean absorption coefficients for CO.

\begin{tabular}{lll}
\hline$a_{p, \mathrm{CO}}$ & $T \leq 750 \mathrm{~K}$ & $T>750 \mathrm{~K}$ \\
\hline$c_{0, \mathrm{CO}}$ & $+0.47869 \times 10^{1}$ & $+0.10090 \times 10^{2}$ \\
$c_{1, \mathrm{CO}}$ & $-0.69530 \times 10^{-1}$ & $-0.1183 \times 10^{-1}$ \\
$c_{2, \mathrm{CO}}$ & $+0.29577 \times 10^{-3}$ & $+0.47753 \times 10^{-5}$ \\
$c_{3, \mathrm{CO}}$ & $-0.42573 \times 10^{-6}$ & $-0.58721 \times 10^{-9}$ \\
$c_{4, \mathrm{CO}}$ & $+0.20289 \times 10^{-9}$ & $-0.25334 \times 10^{-13}$ \\
\hline
\end{tabular}

Frank et al. [14] measured total radiant fractions of 5.1\% and 3.0\% for flames $\mathrm{D}$ and $\mathrm{F}$, respectively, whereas the current predicted values up to $x / D=80$ are $7.4 \%$ and $4.0 \%$. The differences between computed and measured values are arguably consistent with the optically thin flame approximation. More comprehensive treatment of the radiative heat losses is possible (e.g., [8]) though the predominant uncertainties downstream in the flame $(x / D \geq 50)$ are associated with the rate of spread.

\section{Results for Turbulent Flames}

The current work on laminar flames indicates that the rates for the prompt NO formation determined by Dean et al. [11] and Miller and Walch [27] bracket current uncertainties and the objective here is to explore the effects of the two aforementioned rates on computed $\mathrm{NO}$ levels in turbulent flames. To this effect, calculations corresponding to the experimental data of Barlow and co-workers [1,2] for Flames $\mathrm{B}, \mathrm{D}$ and $\mathrm{F}$ have been performed.

The conditional statistics of scalars presented below are defined as the massweighted means of any scalar variable $Y_{\phi}$ conditioned on $f=\psi$ by $\left\langle\rho Y_{\phi}\right| f=$ $\psi\rangle /\langle\rho\rangle$, where $\psi$ is the mixture fraction sample space. At a specific axial location (e.g., $x / D=15$ ), the conditional means are extracted by consideration of all Lagrangian particles that lie in the single strip of cells in the radial direction centered on that location. In the experiment, the conditional means are constructed in a similar fashion from data at all radial locations. A total of 40 bins in mixture fraction space are used for this calculation.

The computed conditional averages of temperature in mixture fraction space at $x / D=15$ for Flames B, D and $\mathrm{F}$ are compared with measurements in Figure 4. The agreement may be considered satisfactory. The two different rates considered for the prompt NO channel lead to almost identical temperature predictions and only calculations corresponding to the rate of Miller and Walch [27] are shown. Predictions of reactive scalars for Flame $\mathrm{B}$ at $x / D=15$ are shown in Figure 5. The overall agreement is satisfactory and the effects of radiative heat losses remain small at this axial location. The only notable disagreement concerns the $\mathrm{H}_{2}$ profile which is over-predicted by $\sim 50 \%$. The discrepancy vanishes at higher $R e$ 


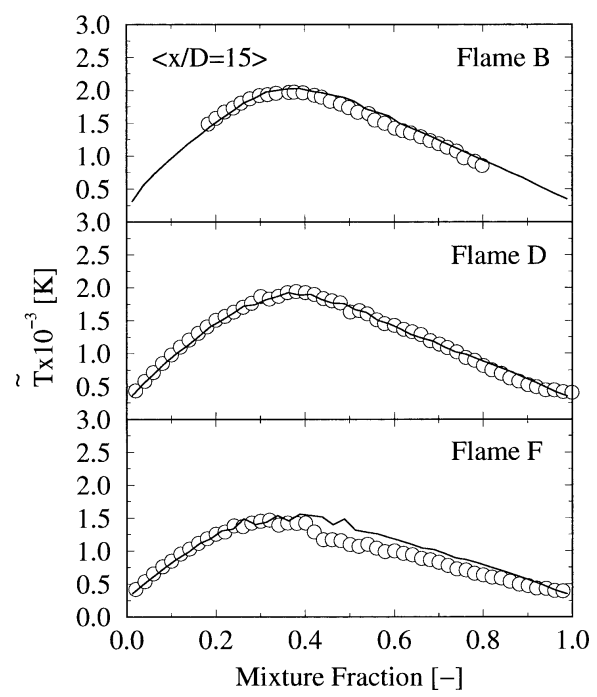

Figure 4. Radial profiles of temperature in mixture fraction space at $x / D=15$ for Flames B, $\mathrm{D}$ and $\mathrm{F}$. The symbols represent experimental data [2] and the lines predictions obtained with the rate of Miller and Walch [27].

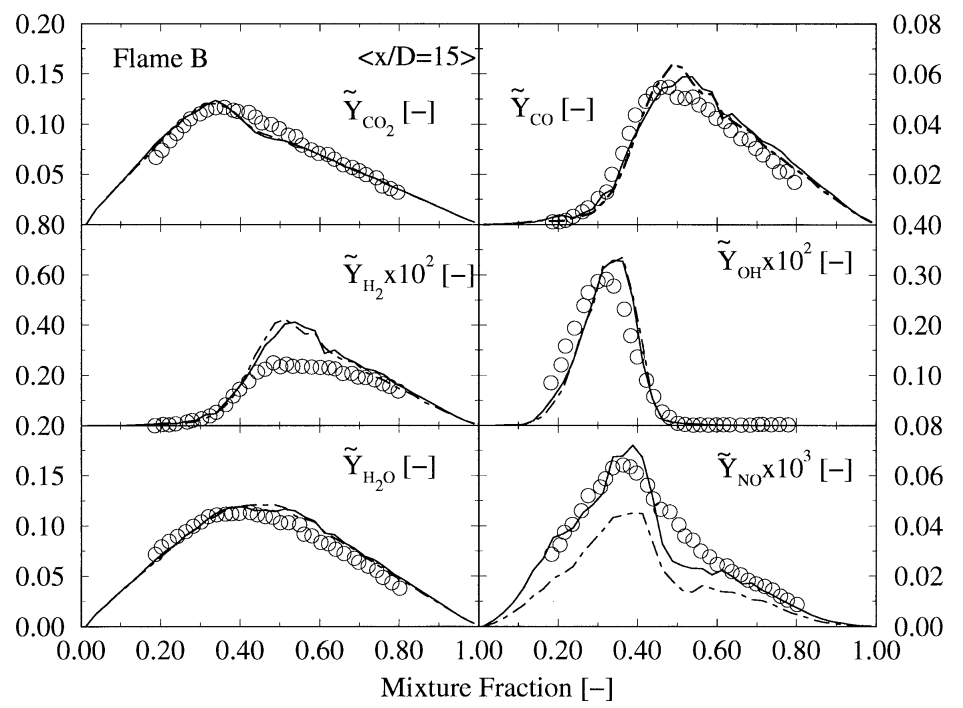

Figure 5. Radial profiles of species mass fractions in mixture fraction space at $x / D=15$ for Flame B. The symbols represent experimental data [2] and the lines predictions obtained with the rate of Dean et al. [11] (solid line) and Miller and Walch [27] (dot-dashed line).

numbers (e.g., Flame D) and could be an indication of differential diffusion effects. However, key reactions, such as $\mathrm{CO}+\mathrm{OH}=\mathrm{CO}_{2}+\mathrm{H}$ which governs the $\mathrm{CO}$ to $\mathrm{CO}_{2}$ conversion, do not appear to be strongly affected. As far as $\mathrm{NO}$ is concerned, excellent predictions are obtained with the rate of Dean et al. [11], whereas the rate 


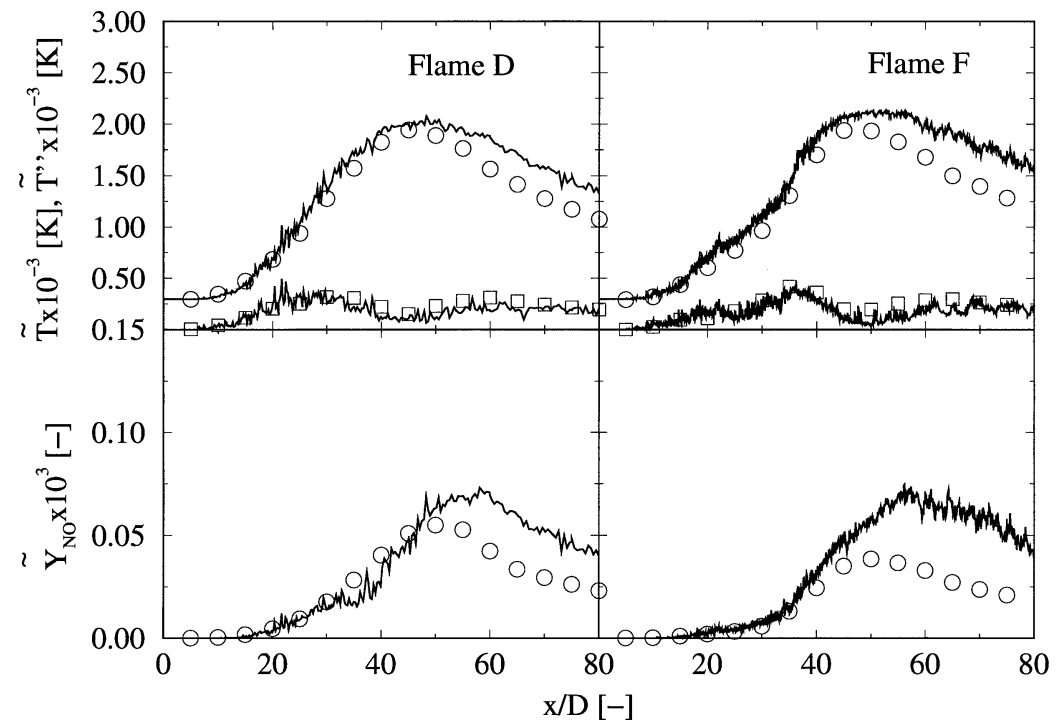

Figure 6. Axial profiles of temperature, its rms and $\mathrm{NO}$ mass fraction for flames D and $\mathrm{F}$. The symbols and lines are as in Figure 4.

of Miller and Walch [27] results in under-predicted peak NO levels by $~ 30 \%$. No other experimental data are available for Flame B and the overall level of agreement is encouraging given the low Reynolds number $(R e \sim 8200)$.

Predictions of NO mass fractions obtained with the two rates are also presented for Flames D and F. The measurements include axial profiles, radial profiles in physical and mixture fraction space at different jet locations, scatter data as well as conditional PDFs. Figure 6 shows the axial profiles of temperature, its rms and NO mass fractions for Flames D and F. Excellent agreement is obtained for temperature for both flames computed up to $x / D=50$, while further downstream the temperature is over-predicted by up to $250 \mathrm{~K}$. The discrepancies may be attributed to the use of a gradient diffusion closure, using a constant "turbulent" Prandtl number, for the turbulent transport of the PDF. Over-predictions of NO levels by up to a factor of 2 and 2.5 for Flames D and F, respectively, follow the temperature over-prediction. Such over-predictions for Flame D have also been reported by Coelho and Peters [7], Pitsch and Steiner [30] and Roomina and Bilger [32].

Figure 7 presents the distribution of temperature and its rms in physical space for Flames D and F. The results shown here feature the rate of Miller and Walch [27]. Comparisons between experimental data and computed results show that for both cases the rate of spread is well predicted. Moreover, the low mean temperatures observed for Flame $\mathrm{F}$ at $x / D=15$ indicate that the computations predict significant amounts of partial extinction at this location. On the other hand, over-predictions of the peak temperatures at the centre-line are observed for both flames at $x / D=60$.

Predictions of the NO mass fraction distribution in physical space for Flames $\mathrm{D}$ and $\mathrm{F}$ are shown in Figures 8 and 9, respectively. Inspection reveals that up to 


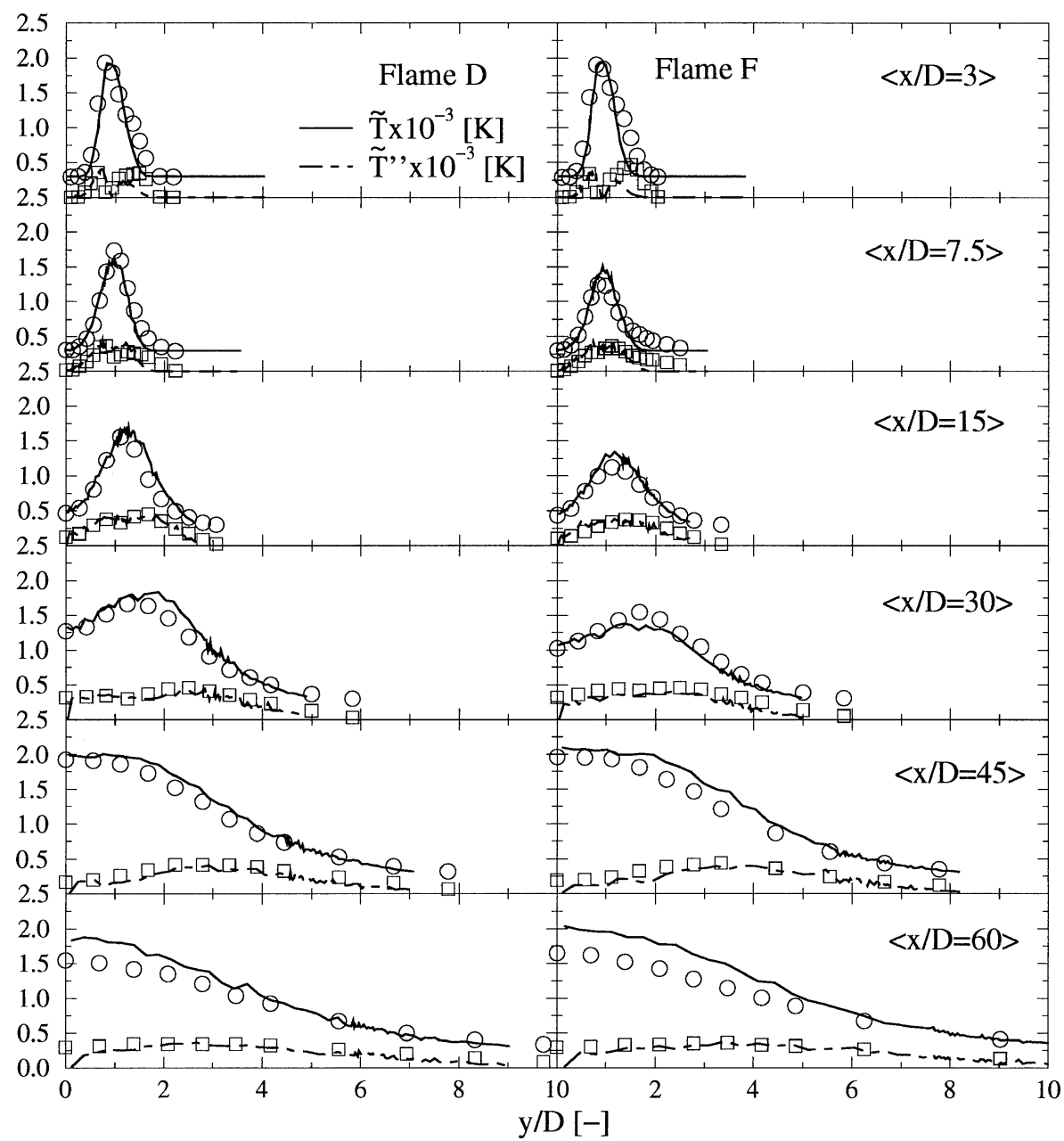

Figure 7. Radial profiles of temperature and its rms for Flames D and F. The symbols and lines are as in Figure 4.

$x / D=45$ good agreement is achieved for Flame $\mathrm{D}$, whereas at $x / D=60$, both rates lead to an over-prediction of the NO levels close to the centre-line, following the temperature over-prediction at the same location. In contrast to the current results, the corresponding predictions of Coelho and Peters [7] and Roomina and Bilger [32] have provided NO peak values twice those measured. Encouraging results are also obtained for Flame F, where the rate of Miller and Walch [27] tends to provide satisfactory agreement.

Figures 10 and 11 show the evolution of the NO mass fraction in mixture fraction space for Flames D and F, respectively. The overall agreement is very satisfactory and the two rate determinations essentially bracket the experimental data. Arguably, the rate determination of Miller and Walch [27] results in better 


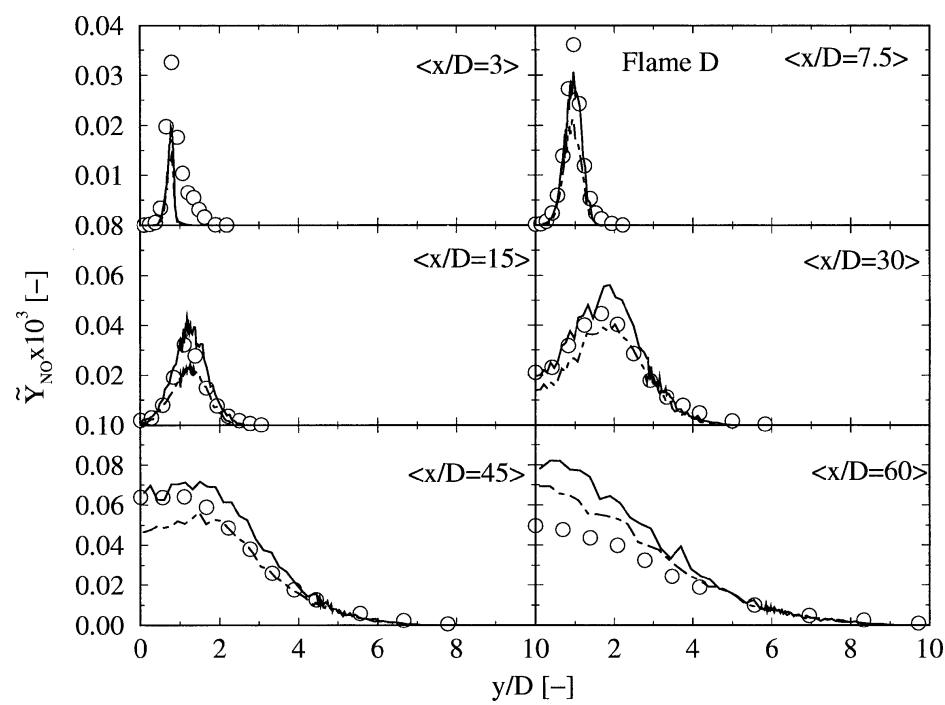

Figure 8. Radial profiles of NO mass fraction for Flame D. The symbols and lines are as in Figure 5.

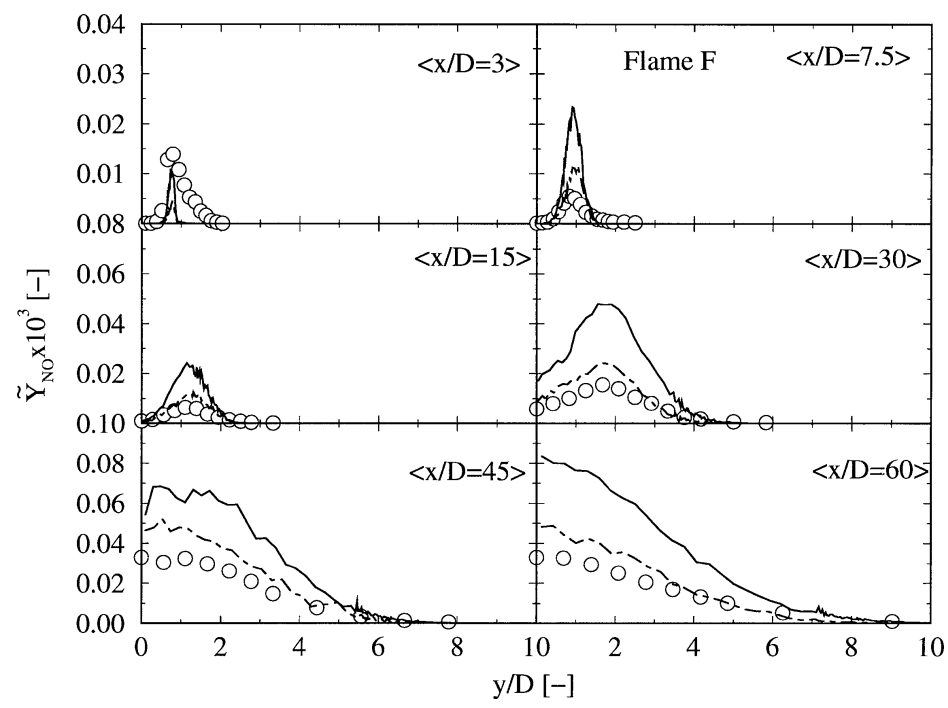

Figure 9. Radial profiles of NO mass fraction for Flame F. The symbols and lines are as in Figure 5.

agreement with experimental data and this finding is consistent with the work in laminar flames. However, other thermochemical uncertainties may well influence the current finding and quantitative determinations of $\mathrm{CH}$ radical concentrations would be very beneficial. With the exception of the first measurement station, the NO concentrations for Flame F are consistently over-predicted indicating that the computations predict less local extinction than measured. However, the flame is very 


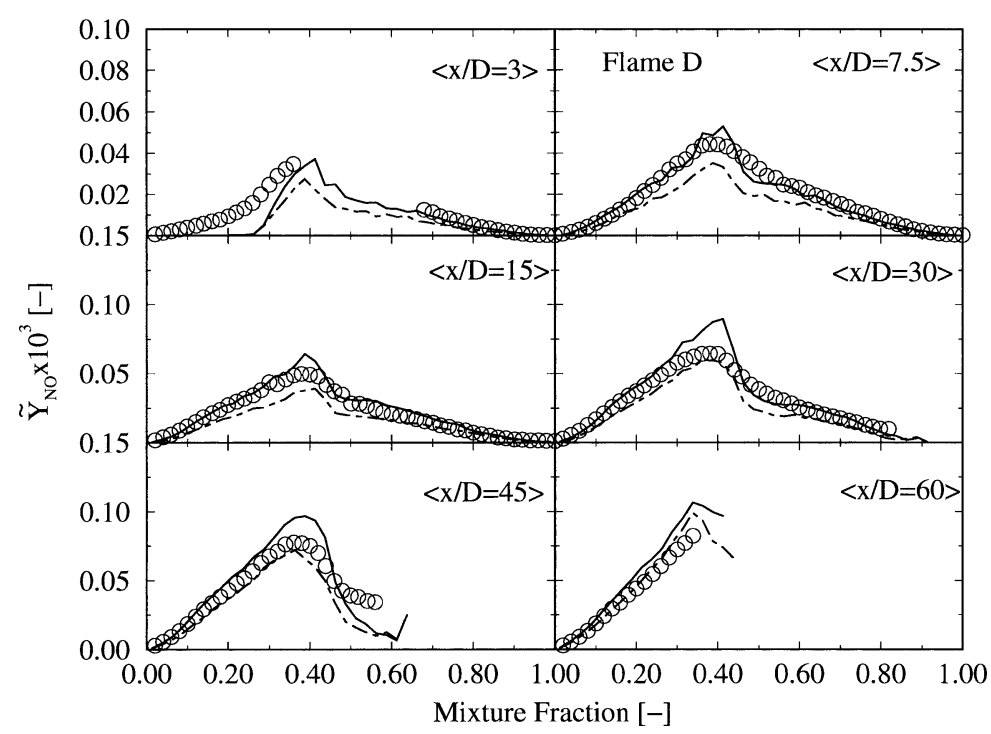

Figure 10. Radial profiles of NO mass fraction in mixture fraction space for Flame D. The symbols and lines are as in Figure 5.

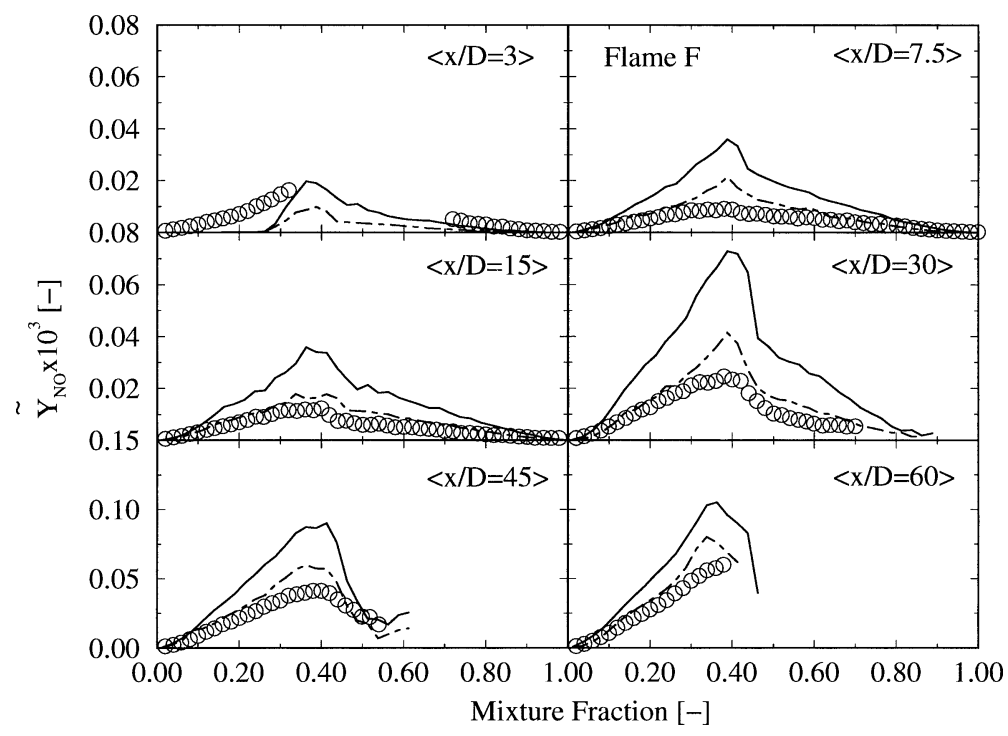

Figure 11. Radial profiles of NO mass fraction in mixture fraction space for Flame F. The symbols and lines are as in Figure 5.

sensitive to boundary conditions and no attempt was made to improve the agreement further. Scatter plots of NO mass fraction versus mixture fraction at $x / D=15$, 30 and 45 are presented in Figures 12 and 13 for Flames D and F, respectively, with the predictions featuring the rate of Miller and Walch [27]. Laminar flamelet data obtained with the same mechanism used in the laminar flame calculations 


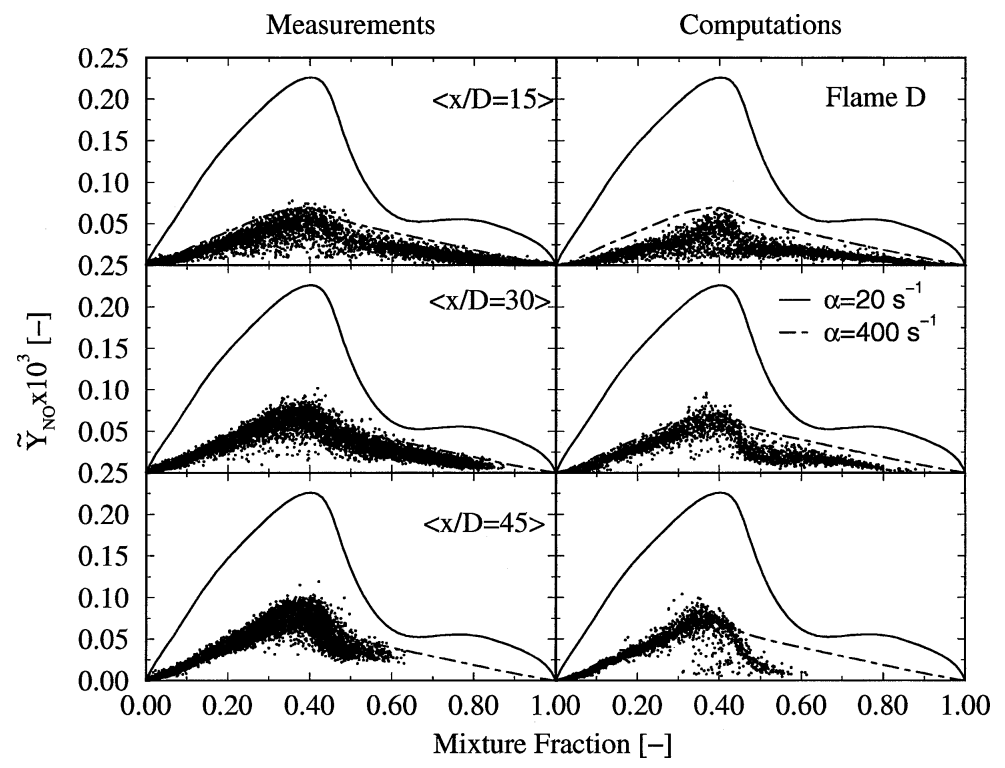

Figure 12. Measurements and computations of NO mass fraction obtained with the rate of Miller and Walch [27] in mixture fraction space at $x / D=15,30$ and 45 for Flame D.

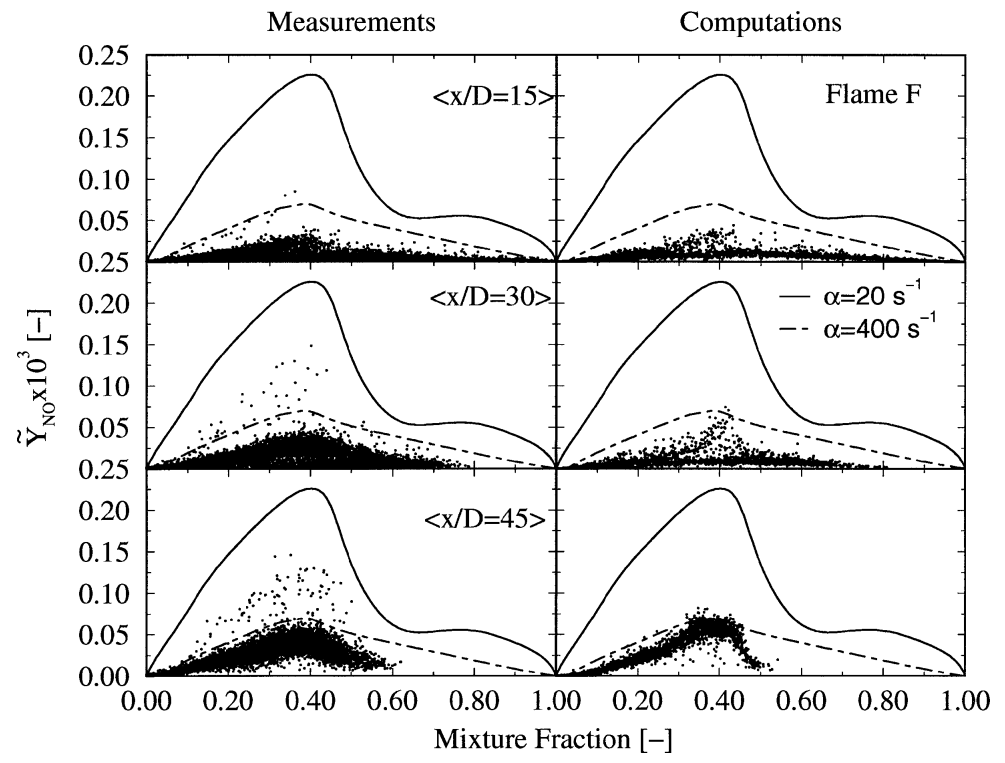

Figure 13. Measurements and computations of NO mass fraction obtained with the rate of Miller and Walch [27] in mixture fraction space at $x / D=15,30$ and 45 for Flame F.

shown above are also shown for two rates of strain $\left(\alpha=20 \mathrm{~s}^{-1}\right.$ and $\left.\alpha=400 \mathrm{~s}^{-1}\right)$. The higher value corresponds to a flame approaching extinction. The calculations feature an equal diffusivity approximation and the $25 \% \mathrm{CH}_{4} / 75 \%$ air fuel stream of the equivalent turbulent flames. The calculations suggest that the flames are subject 


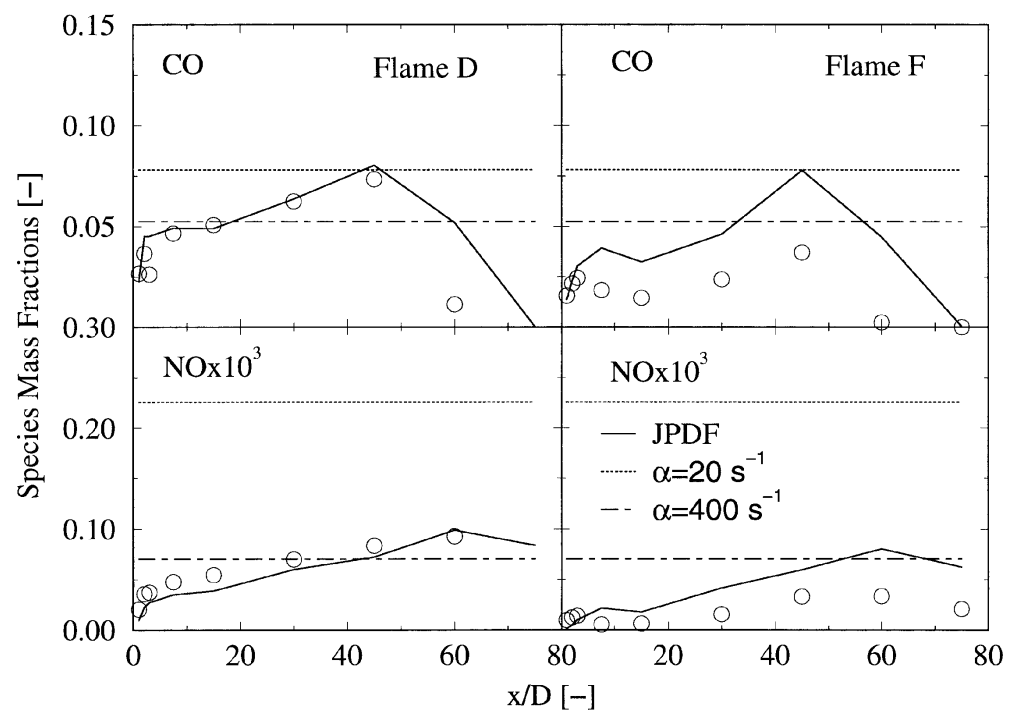

Figure 14. Axial profiles of peak values of species conditional averages in mixture fraction space for Flames D and F. The circles represent experimental data [2] and the lines predictions obtained with the JPDF method (solid line) and the laminar flamelet approach with $\alpha=20 \mathrm{~s}^{-1}$ (dotted line) and $\alpha=400 \mathrm{~s}^{-1}$ (dot-dashed line). All computations feature the rate of Miller and Walch [27].

to high rates of strain and that significant departures from the steady-state flamelet approximation are present. The peak values of conditional averages of $\mathrm{CO}$ and NO in mixture fraction space were selected at all locations where measurements are available. The resulting axial profiles are compared with the corresponding experimental data and laminar flamelet calculations in Figure 14.

The computed conditional PDFs of NO mass fraction featuring the rate of Miller and Walch [27] are compared with measurements at $x / D=15,30$ and 45 for Flames D and F in Figure 15. The former are extracted from particles in a specified mixture fraction range $\left(f_{l} \leq f \leq f_{u}\right)$. The mixture fraction range is specified in accordance with Barlow and Frank [2]. In general, as the distance from the nozzle increases, the PDF is shifted towards higher values of NO concentrations. This trend is captured reasonably well by the computations. The evolution of the shape of the PDF also appears well reproduced.

\section{Conclusions}

In the present work, a transported PDF approach, closed at the joint scalar level, is coupled with a comprehensive chemistry description and applied to a range of turbulent $\mathrm{CH}_{4} / \mathrm{O}_{2} / \mathrm{N}_{2}$ diffusion flames. It is shown that the radiative heat losses can be reproduced with satisfactory accuracy and that predictions of oxides of nitrogen in the current turbulent flames are primarily linked to the level of sophistication in 


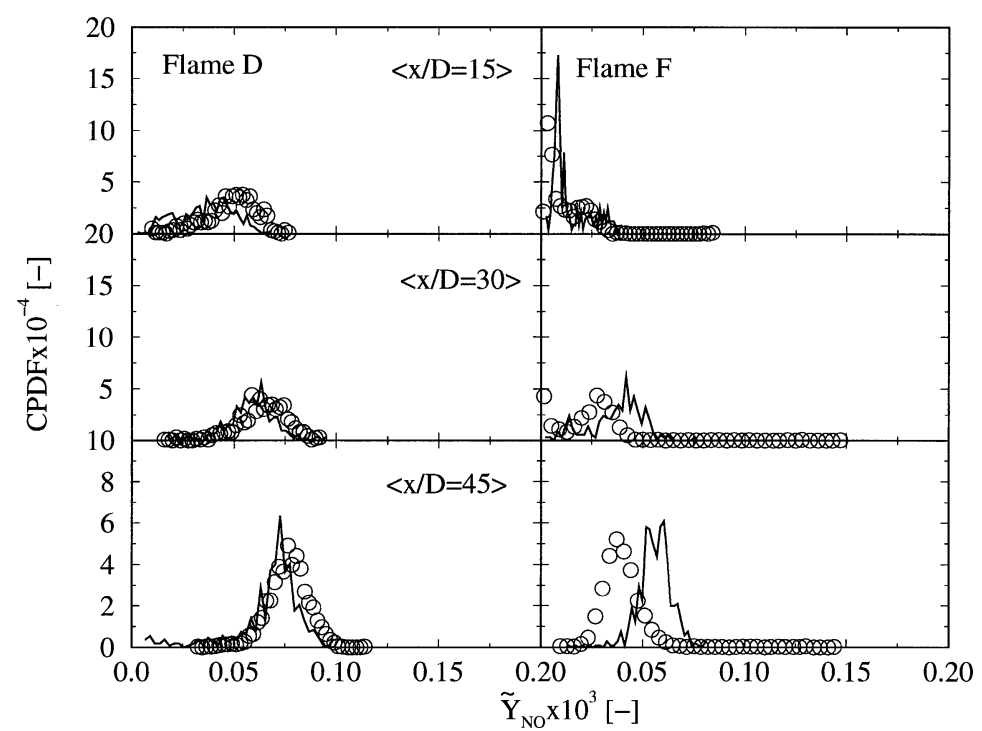

Figure 15. Measurements and computations of the conditional pdf's $(0.33 \leq \tilde{f} \leq 0.41)$ of NO mass fraction at $x / D=15,30$ and 45 for Flames $\mathrm{D}$ and $\mathrm{F}$. The symbols and lines are as in Figure 4.

the chemical closure rather than other factors (e.g., differential diffusion effects). In particular, the formation rate for the prompt NO channel has been shown to be of paramount importance and results obtained are fully consistent with those observed in laminar flames. The calculations also show that the evolution of the shape of the conditional PDF of NO is captured even in the presence of local extinction and re-ignition. It is suggested that quantitative determinations of the $\mathrm{CH}$ radical in both laminar and turbulent flames would be very beneficial in order to resolve remaining thermochemical issues. Additionally, the significant uncertainties regarding the scalar dissipation rate appearing in the closure for the molecular mixing term must also be resolved, due to the significant influence on extinction and re-ignition phenomena.

\section{Acknowledgments}

R.P. Lindstedt and S.A. Louloudi wish to express their gratitude to the EPSRC for financial support under grant GR/L23413. The work by J.J. Driscoll and V. Sick was supported by the National Science Foundation under Grant No. CTS 0087337.

\section{References}

1. Barlow, R., www.ca.sandia.gov/TNF, (2000).

2. Barlow, R. and Frank, J., Effects of turbulence on species mass fractions in methane/air jet flames. In: Proceedings Combustion Institute, Vol. 27 (1998) pp. 1087-1095. 
3. Barlow, R., Karpetis, A., Frank, J. and Chen, J.-Y., Scalar profiles and NO formation in laminar opposed-flow partially premixed methane/air flames. Combust. Flame 127 (2001) 2102-2118.

4. Berg, P., Smith, G., Jeffries, J. and Crosley, D., Nitric oxide formation and reburn in low-pressure methane flames. In: Proceedings Combustion Institute, Vol. 27 (1998) pp. 1377-1384.

5. Brockhinke, A., Bülter, A., Rolon, J. and Kohse-Höinghaus, K., Ps-LIF measurements of minor species concentrations in a counterflow diffusion flame interacting with a vortex. Appl. Phys. B 72 (2001) 491-496.

6. Carter, C. and Barlow, R., Simultaneous measurements of $\mathrm{NO}, \mathrm{OH}$ and the major species in turbulent flames. Opt. Lett. 19 (1994) 299-301.

7. Coelho, P. and Peters, N., Unsteady modelling of piloted methane/air jet flame based on the eulerian particle flamelet model. Combust. Flame 124 (2001) 444-465.

8. Coelho, P., Teerling, J. and Roekaerts, D., Spectral radiative effects and turbulence/radiation interaction in a non-luminous turbulent jet diffusion flame. Combust. Flame 133(1) (2003) 75-91.

9. Daily, J., Laser induced fluorescence spectroscopy in flames. Prog. Energy Combust. Sci. 23 (1997) 133-199.

10. Daly, B. and Harlow, F., Transport equations in turbulence. Phys. Fluids 13 (1970) 2634-2649.

11. Dean, A., Hanson, R. and Bowman, C., High temperature shock tube study of reactions of $\mathrm{CH}$ and C-Atoms with $\mathrm{N}_{2}$. In: Proceedings Combustion Institute, Vol. 23 (1991) pp. 259-265.

12. Driscoll, J., Sick, V., Farrow, R. and Schrader, P., Measurements of NO distributions and fluorescence lifetimes in a non-premixed counterflow $\mathrm{CH}_{4}$ /air flame using picosecond time-resolved laser-induced fluorescense. In: Proceedings Combustion Institute, Vol. 29 (2002) pp. 2719_ 2726.

13. Evertsen, R., van Oijen, J., Hermanns, R., de Goey, L. and ter Meulen, J., Measurements of absolute concentrations of $\mathrm{CH}$ in a premixed atmospheric flat flame by cavity ringdown spectroscopy. Combust. Flame 132(1) (2003) 34-42.

14. Frank, J., Barlow, R. and Lundquist, C., Radiation and nitric oxide formation in turbulent nonpremixed jet flames. In: Proceedings Combustion Institute, Vol. 28 (2000) pp. 447-454.

15. Frenklach, M., Wang, H., Goldenberg, M., Smith, G., Golden, D., Bowman, C., Hanson, R., Gardiner, W. and Lissianski, V., GRI Mech 2.11. Report GRI-95/0058, Gas Research Institute Topical Report (1995).

16. Grosshandler, W., RADCAL: A Narrow-Band Model for Radiation Calculations in a Combustion Environment. NIST Technical Note 1402 (1993).

17. Hůlek, T. and Lindstedt, R., Joint scalar-velocity PDF modelling of finite rate chemistry in a scalar mixing layer. Combust. Sci. Technol. 136(1-6) (1998) 303-331.

18. Janicka, J., Kolbe, W. and Kollmann, W., Closure of the transport equation for the probability density function of scalar fields. J. Non-equilib. Thermodyn. 4(1) (1979) 47-66.

19. Jones, W., Turbulence modelling and numerical solution methods for variable density and combusting flows. Turbulent Reacting Flows. Academic Press, Chapt. 6 (1993) 309-374.

20. Juchmann, W., Latzel, H., Shin, D., Peiter, G., Dreier, T., Volpp, H., Wolfrum, J., Lindstedt, R.P. and Leung, K.M., Absolute radical concentration measurements and modelling of lowpressure $\mathrm{CH}_{4} / \mathrm{O}_{2} / \mathrm{NO}$ flames. In: Proceedings Combustion Institute, Vol. 27 (1998) pp. 469476.

21. Lindackers, D., Burmeister, M. and Roth, P., Perturbation studies of high temperature $\mathrm{C}$ and $\mathrm{CH}$ reactions with $\mathrm{N}_{2}$ and NO. In: Proceedings Combustion Institute, Vol. 23 (1991) pp. 251-257.

22. Lindstedt, R., Lockwood, F. and Selim, M., A detailed kinetic study of ammonia oxidation. Combust. Sci. Technol. 108 (1995) 231-254.

23. Lindstedt, R., Louloudi, S. and Váos, E., Joint scalar probability density function modelling of pollutant formation in piloted turbulent jet diffusion flames with comprehensive chemistry. In: Proceedings Combustion Institute, Vol. 28 (2000) pp. 149-156. 
24. Markus, M., Roth, P. and Just, T., A shock tube study of the reactions of $\mathrm{CH}$ with $\mathrm{CO}_{2}$ and $\mathrm{H}_{2}$ O. Int. J. Chem. Kinet. 28 (1996) 171.

25. Mercier, X., Pillier, L., Bakali, A.E., Carlier, M., Pauwels, J.-F. and Desgroux, P., NO reburning study based on species quantification obtained by coupling LIF and cavity ring-down spectroscopy. Faraday Discuss. 119 (2001) 305-319.

26. Miller, J. and Bowman, C., Mechanism and modeling of nitrogen chemistry in combustion. Prog. Energy Combust. Sci. 15 (1989) 287-338.

27. Miller, J. and Walch, S., Prompt NO: Theoretical prediction of the high-temperature rate coefficient for $\mathrm{CH}+\mathrm{N}_{2}=\mathrm{HCN}+\mathrm{N}$. Int. J. Chem. Kinet. 29 (1997) 253-259.

28. Paul, P., Gray, J., Durant, J. and Thoman, J., Collisional electronic quenching rates for NO A(2) $\Sigma(+)\left(\epsilon^{\prime}=0\right)$. Chem. Phys. Lett. 259 (1996) 508-514.

29. Paul, P., Gray, J., Durant, J. and Thoman, J., Collisional quenching corrections for laser-induced fluorescence measurements of NO A(2) $\Sigma+$. AIAA J. 32 (1996) 1670-1675.

30. Pitsch, H. and Steiner, H., Large-eddy simulation of a turbulent piloted methane/air diffusion flame (Sandia Flame D). Phys. Fluids 12(10) (2000) 2541-2554.

31. Renfro, M., Klassen, M., King, G. and Laurendeau, N., Time-series measurements of CH concentration in turbulent $\mathrm{CH}_{4}$ /air diffusion flames by use of picosecond time-resolved laserinduced fluorescence. Opt. Lett. 22 (1997) 175-177.

32. Roomina, M. and Bilger, R., Conditional moment closure (CMC) predictions of a turbulent methane-air jet flame. Combust. Flame 125 (2001) 1176-1195.

33. Schwarzwald, R., Monkhouse, P. and Wolfrum, J., Fluorescence lifetimes for nitric oxide in atmospheric pressure flames using picosecond excitation. Chem. Phys. Lett. 158 (1989) 60-64.

34. Shin, D., Dreier, T. and Wolfrum, J. Spatially resolved absolute concentration of fluorescencelifetime determination of $\mathrm{H}_{2} \mathrm{CO}$ in atmospheric-pressure $\mathrm{CH}_{4} /$ air flames. Appl. Phys. B $\mathbf{7 2}$ (2001) 257-261.

35. Sick, V., Hildenbrand, F. and Lindstedt, R., Quantitative laser-based measurements and detailed chemical kinetic modelling of nitric oxide concentrations in methane-air counterflow diffusion flames. In: Proceedings Combustion Institute, Vol. 27 (1998) pp. 1401-1409.

36. Speziale, C., Sarkar, S. and Gatski, T., Modelling the pressure-strain correlation of turbulence: An invariant dynamical systems approach. J. Fluid Mech. 227 (1991) 245-272.

37. Tamura, M., Berg, P., Harrington, J., Luque, J., Jeffries, J., Smith, G. and Crosley, D., Collisional quenching of $\mathrm{CH}(\mathrm{A}), \mathrm{OH}(\mathrm{A})$, and $\mathrm{NO}(\mathrm{A})$ in low-pressure hydrocarbon flames. Combust. Flame 144 (1998) 502-514.

38. Tang, Q., Xu, J. and Pope, S., PDF Calculations of local extinction and NO production in piloted-jet turbulent methane/air flames. In: Proceedings Combustion Institute, Vol. 28 (2000) pp. 133-139.

39. Tsujishita, M. and Hirano, A., Two-dimensional quenching lifetime measurements of $\mathrm{OH}$ : $\mathrm{A}(2)$ $\Sigma(+)\left(v^{\prime}=1\right)$ and NO: A (2) $\Sigma(+)\left(v^{\prime}=0\right)$ in atmospheric pressure flames. Appl. Phys. B. 62 (1996) 255-262.

40. Yaney, P., Kliner, D., Schrader, P. and Farrow, R., Distributed feedback dye laser for picosecond ultraviolet and visible spectroscopy. Rev. Sci. Instrum. 71 (2000) 1296-1305.

41. Zabarnick, S., Fleming, J. and Lin, M., Temperature dependence of $\mathrm{CH}$ radical reactions with $\mathrm{H}_{2} \mathrm{O}$ and $\mathrm{CH}_{2} \mathrm{O}$. In: Proceedings Combustion Institute, Vol. 21 (1986) pp. 713-719. 